1 Erythrocyte indices, anaemia levels and types in Kenyan injection and non-injection

\title{
substance users
}

3 Emmanuel Mulaya Khazalwa ${ }^{1}$, Tom Were ${ }^{2 *}$, David Hughes Mulama ${ }^{1}$, Valentine Budambula ${ }^{3}$

5 Emmanuel Mulaya Khazalwa ${ }^{1}$

6 Email: emmanuelbahati235@gmail.com

7

8 Tom Were 2* $^{*}$

9 Email: mugogwe@yahoo.com

10 David Hughes Mulama ${ }^{1}$

11 dmulama@gmail.com

12

13

Valentine Budambula ${ }^{3}$

14 Email: valbudambula@gmail.com

15

16

$17{ }^{1}$ Department of Biological Sciences, Masinde Muliro University of Science and Technology,

18 Kakamega, Kenya.

$19{ }^{2}$ Department of Medical Laboratory Science, Masinde Muliro University of Science and

20 Technology, Kakamega, Kenya.

$21{ }^{3}$ Department of Health Sciences, Technical University of Mombasa, Mombasa, Kenya.

*Corresponding author

E-mail: mugogwe@yahoo.com

27

28 Authors Contribution: "TW and VB designed the study", "EMK, TW and VB conducted data collection and laboratory studies", "TW and EMK, data analysis, interpretation and codrafted the manuscript", "DHM critically revised the manuscript for important intellectual

31 content". 


\section{Abstract}

34 The impact of injection and non-injection substance use in HIV infections is an area of great public importance especially with respect to hematologic and immune profiles. Evaluations of hematologic and immune status are critical for better disease classification and clinical management especially of HIV positive substance users. However, not much information is known about the hematologic and immune derangements in HIV infected injection and noninjection substance users. This study, therefore, aimed at determining the laboratory markers of hematologic and immune derangements in HIV infected substance users. Hematologic and immune profiles were evaluated on venous blood specimens obtained from injection substance users, ISU (HIV-infected, $\mathrm{n}=62$ and -uninfected, $\mathrm{n}=213$ ) and non-injection substance users (HIV-infected, $\mathrm{n}=33$ and -uninfected, $\mathrm{n}=186$ ); and non-substance using controls $(n=56)$ from Mombasa, coastal town of Kenya. The prevalence of anemia was higher in HIV infected ISU (48.4\%) and non-ISU (63.6\%) $(\mathrm{p}<0.0001)$; and HIV uninfected ISUs (56.3\%) compared to HIV-uninfected non-ISUs (39.2\%) and non-substance using controls (28.6\%; $\mathrm{p}=0.0028)$. Hypochromic anaemia was more prevalent in the HIV-infected ISU (50.0\%) and non-ISU (61.9\%), and HIV-negative ISU (63.3\%) relative to the HIV-negative non-ISU (39.7\%) and non-substance using controls (56.3\%; $\mathrm{p}=0.0007)$. Mild immunodeficiency dominated in the HIV infected individuals (HIV-infected ISU, 32.3\% and non-ISU, 21.2\%) versus HIV-uninfected ISU (16.9\%); non-ISU (12.9\%); and non-substance users $(14.3 \%)$ while severe immunosuppression prevailed in HIV infected substance users (ISU, 14.5\% and non-ISU, 15.2\%) against HIV uninfected substance users (ISU, 5.2\% and non-ISU, 3.8\%); thus immunosuppression in substance users is aggravated with HIV infection. Moreover, drug-induced immunosuppression is associated with a higher likelihood of anaemia in HIV-uninfected substance users; ISU $(\mathrm{OR}=3.95, \mathrm{CI}=1.934-8.077, \mathrm{p}<0.0001)$ and non-ISU $(\mathrm{OR}=3.63, \mathrm{CI}=1.571-8.39, \mathrm{p}=0.003)$. Altogether, hypochromic anaemia, normochromic anaemia and CD4+ T-helper cytopenia are the most prevalent hemocytopenias in HIV infected and uninfected injection and non-injection substance users. 


\section{Introduction}

62 Of the 36.9 million people living with HIV/AIDS in the world, 25.8 million reside in Sub63 Saharan Africa (1). In addition, out of the 2 million new HIV infections globally, 1.4 million are recorded in Sub-Saharan Africa $(1,2)$. Substance use has been implicated in the soaring HIV burden and HIV-disease progression in the world (3-20). For instance, the United Nations Office on Drugs and Crime (UNODC) report published in 2018 indicates that $12.5 \%$ of Injection Substance Users (ISU) were infected with HIV by the end of 2017 with $5.6 \%$ of the global population having used illicit substances (21-25). Injection drug use has been described as one of the major factors that propel the HIV burden worldwide through the practice of sharing hypodermic needles and engaging in unprotected sex with drug and nondrug users $(6,26,27)$ heightening HIV transmission in injection drug users compared to the general population (5). In addition, People-Who-Inject-Drugs (PWID) make up 30\% of the new HIV infections in the world $(28,29)$. Non-injection substance use also increases the risk of HIV infection due to altered judgment and increased risky sexual behaviours in non-ISU $(9,22,30)$. Both illicit substance use and HIV infections are increasing in the African continent especially in urban and coastal regions $(10,23,24,26,31-38)$. There are 1.02 million ISUs in Africa out of whom 123,420 are infected with $\operatorname{HIV}(1,28,29)$.

HIV infections and illicit substance use have individually been implicated for derangements in the hematologic and immune profiles (5,27,39-49). For instance, HIV infections cause alterations in the hematologic measures. Anaemia, leukopenia and thrombocytopenia are the most frequent hematologic manifestation in HIV-infected individuals (46,50,51). In addition, $\mathrm{CD}^{+}$T-helper lymphocyte counts are decreased in HIV infection; with lower CD4-counts exhibited in HIV-infected persons compared to HIV-uninfected individuals. (52). Immune status is routinely based on CD4+ T-cell counts (53) Likewise, substance use has been associated with haematological and immune perturbations in HIV uninfected injection and non-injection substance users $(26,54)$. For instance, neutrophilia has been observed in heroin and opium addicts $(43,55)$ while neutropenia, eosinopenia and lymphopenia have been associated with the abuse of Marijuana (Cannabis sativa) (56) and chronic alcoholism (57). Monocytosis has been observed in individuals who use Khat (Catha edulis) (58) while monocytopenia associated with Cannabis use and alcoholism hence decreased proliferation and impaired monocyte and macrophage function (56,57). It is, therefore, possible that these derangements in the haematologic and immune profiles are exacerbated in HIV-positive 
94 progression and a strong determinant for the initiation of therapy (59). Thus, assessment of 95 anaemia levels and cellular morphology is important in elucidating the underlying 96 mechanisms associated with these observed blood derangements which will, in turn, support 97 the treatment of drug use by delivering services aimed at reducing the adverse health 98 consequences of substance use. Malnutrition has been observed in both HIV-infected and 99 HIV-uninfected injection substance users (4). Irregular carbohydrate, lipid and protein 100 metabolism have been documented in heroin, crack-cocaine addicts and cigarette smokers 101 (60). HIV-1 viral load in-conjunction with immunosuppression have been utilized as markers 102 of HIV disease progression and the initiation of antiretroviral therapy treatment $(59,61-65)$.

103 HIV-1 disease progression has been observed to increase in heroin abusers $(4,50,66)$. Routine

104 hematologic and immune status evaluations guide disease classification and quality 105 management of patients. However, the interplay between HIV infection and substance use on 106 hematologic profiles has not been reported among substance users in Kenya. This study 107 investigated erythrocyte measures, anaemia (levels, types and aetiology) and its association 108 with under-nutrition, immunosuppression and viral failure in Kenyan illicit substance users. 


\section{Materials and methods}

\section{Study site, design and population}

112 This cross-sectional immune-hematologic study was conducted among HIV-1-positive and

113 HIV-1-negative injection substance (ISU) and non-injection substance (non-ISU) users in

114 Mombasa, a coastal Kenyan city. All HIV-1-positive participants in this study had not been

115 previously initiated on any antiretroviral treatment regimen. The detailed description of the

116 study site and study population are published elsewhere (30). The study population was

117 stratified as follows: 1). HIV-positive Injection substance users (HIV+ISU+); 2). HIV-

118 negative Injection Substance Users (HIV-ISU+); 3). HIV-positive non-injection substance

119 users (HIV+ISU-); 4) HIV-negative non-injection substance users (HIV-ISU-) and 5).

120 controls, who never consumed any of the illicit substances as described in the UNODC

121 registry $(28,29)$.

\section{Ethical considerations}

123 Ethical approvals for the study was obtained from the Kenyatta University (Protocol $124 \mathrm{KU} / \mathrm{R} / \mathrm{COMM} / 51 / 32-4)$ and the Masinde Muliro University of Science and Technology 125 (Protocol MMU/COR:403012-vol2[8]) institutional review board (IRB). All the respondents 126 were exhaustively educated as per the recommended guidelines (67) and written informed 127 consent obtained prior to enrollment.

\section{Body mass index (BMI)}

129 Anthropometric measures were obtained from each study participants at enrolment as per the

130 Centres of Disease Control guidelines (68). Height (m) was measured to the nearest $0.1 \mathrm{~cm}$ 131 using the Health-o-meter PORTROD wall mounted height rod (Health O meter ${ }^{\circledR}$, McCook, 132 USA). Study participants were weighed in kilograms $(\mathrm{kg})$ using a portable digital weight 133 scale (Richforth Electronics Co., Fuzhou, China). The BMI was calculated using the height 134 and weight measurements as previously described (68) and $\mathrm{BMI}<18.5 \mathrm{Kg} / \mathrm{m}^{2}$ defined as 135 underweight.

\section{Collection of blood samples}

$1385 \mathrm{ml}$ of venous blood samples was collected from the freely consenting participants by a 139 certified phlebotomist using a vacutainer assembly into two EDTA and Serum Separating 140 Tubes (SST), BD vacutainer ${ }^{\mathrm{TM}}$ tubes (BD, Franklin Lakes, USA). Blood was collected 
141 between $8.00 \mathrm{am}$ and $10.00 \mathrm{am}$ prior to the participants having breakfast to control for the

142 haematological changes due to the circadian rhythm and nutritional status hence obtaining

143 strictly comparable values. All laboratory tests were performed within two hours of sample

144 collection to maintain sample integrity. EDTA blood was used for haematological analysis

145 while SST was used for serum extraction in HIV-1 viral load quantification.

\section{Hematologic measurements}

147 Complete Blood Counts were done within the first hour of blood collection using the 148 quantitative BC-3200 Mindray auto-haematology analyser (Mindray ${ }^{\mathrm{TM}}$ Inc., Mahwah, USA).

149 Anaemia levels and types were classified based on haemoglobin concentration prescribed by 150 the World Health Organization (41) while anaemia aetiology was classified based on bloodmarkers, cellular morphology and staining characteristics (54-56).

\section{Preparation of blood slides}

153 Thin blood films were made on new microscope slides (labelled with participant ID) to prevent cell aggregation and stain precipitation. Back up smears were also made. The thin smears were thoroughly air-dried followed by methanol fixation for 10 minutes. The blood smear was then completely covered with undiluted Leishman Stain which was added dropwise using a bulb-pipette. Twice the volume of buffered water ( $\mathrm{pH}$. 6.8) was gently added and thoroughly mixed. Staining was done for 10 minutes after which the slide was washed off under running tap water. The back of the slide was wiped and the slide placed standing on a draining rack for the smear to dry.

\section{Microscopic analysis}

162 Examination of the stained blood films was done by two independent and blinded hemato-

163 technologists who assessed erythrocyte morphology. Slides with differences of more than $5 \%$ in the results of the two hemato-technologists were re-read by a third independent hemato-technologist. Ten per cent $(\mathrm{n}=55)$ of the read slides were randomly selected and the results confirmed by a haemato-pathologist.

\section{CD4+ T-cell enumeration}

168 Fifty microlitres $(50 \mu \mathrm{l})$ of EDTA anticoagulated blood was stained with anti-CD3

169 fluorescein isothiocyanate (FITC), anti-CD4 phycoerythrin (PE) and anti-CD45 peridinin 170 chlorophyll protein (PerCP) fluorescent-labelled mouse-anti-human monoclonal antibodies 
171 (BD Tri-test Kit ${ }^{\mathrm{TM}}$ ) (62). CD4+ T cell counts were determined using a BD FACSCalibur

172 flow cytometer (Becton-DickinsonTM, Franklin Lakes, USA). CD4+- T-helper cell counts

$173<500$ cells $/ \mu /$ was defined as immunosuppression (69).

\section{HIV-1 viral load determination}

175 RNA was extracted from $200 \mu \mathrm{l}$ of serum in accordance with the Abbott m2000sp sample

176 preparation system protocol. HIV-1 viral loads were then determined using the automated

177 Abbott m2000SP Real-Time System according to the manufacturer's instructions (Abbott

178 Molecular Inc., Illinois, U.S.A). The lower limit of viral load quantification was 150 (2.18

$179 \log _{10}$ ) copies/mL of serum. Virological failure as defined as HIV-1 viral load $\geq 1000$

180 copies/mL (70).

\section{Statistical analysis}

182 Statistical analysis was done in RStudio Version 1.1.383 ( ${ }^{\circ} 2009-2017$ RStudio, Inc.) The continuous variables such as weight, height and BMI that were normally distributed were compared across the groups using a one-way ANOVA test. Absolute CD4 counts and erythrocytic measures were compared using non-parametric ANOVA ( Kruskal-Wallis Test)

186 followed by Bonferroni post-hoc corrections for multiple comparisons. Viral-loads were 187 compared between the two groups using the Mann-Whitney test. Binary logistic regression 188 analysis was performed within each group to examine the association of anaemia, with under189 nutrition, immune-suppression and HIV-1 viral failure; controlling for age, gender, duration 190 and frequency of substance use in injection substance users while age and gender were 191 controlled in the non-injection substance users and controls. All tests were two-tailed and $\mathrm{p}$ values $<0.05$ were considered statistically significant. 


\section{Results}

\section{Anthropometric measurements, CD4 and viral load}

195 Demographic measures, CD4 counts and viral load are as presented in Table 1. A total of 550

196 adults (males, $n=355$ and females, $n=195$ ) were recruited into the study. This comprised of

197 HIV-positive injection substance users (HIV+ISU+, n=62), HIV-negative injection substance 198 users (HIV-ISU+, n=213), HIV-positive non-injection substance users (HIV+ISU-, n=33), 199 HIV-negative non-injection substance users (HIV-ISU-, $\mathrm{n}=186$ ) and non-substance using 200 controls $(n=56)$. The median age (years) was significantly different among the study groups $201(\mathrm{p}=0.0047)$ with posthoc analysis indicating higher median age in HIV+ISU- $(\mathrm{p}=0.0499)$ and 202 HIV-ISU- $(p=0.0112)$ compared to the controls. Median height $(\mathrm{m})$ was different across the study groups $(p<0.0001)$ such that HIV-ISU+ were taller than the HIV+ISU- $(p=0.0061)$ and HIV-ISU- $(\mathrm{p}<0.0001)$. Similarly, weight $(\mathrm{kg})$ differed across the study groups $(\mathrm{p}<0.0001)$ and was higher in HIV+ISU+ than HIV-ISU- $(p<0.0001)$. In addition, under-nutrition rates were higher in HIV+ISU+ (32.3\%), HIV-ISU+ (47.4\%). HIV+ISU- (48.5\%) and HIV-ISU$(22.6 \%)$ compared to the healthy controls $(8.9 \%)$.

CD4 T-helper cell counts varied across the groups $(\mathrm{p}<0.0001)$. These were depressed in HIV+ISU+ (median=519 cells $/ \mu 1, I Q R=471)$ compared to HIV-ISU+ (median=905 cells $/ \mu 1$, $\mathrm{IQR}=639, \mathrm{p}<0.0001)$, HIV-ISU- $($ median=859 cells $/ \mu 1, \mathrm{IQR}=515, \mathrm{p}<0.0001)$ and healthy

211 controls (median=774 cells $/ \mu \mathrm{l}, \mathrm{IQR}=461, \mathrm{p}=0.0014$ ). Moreover, immunosuppression was most prevalent in HIV+ISU+ (46.8\%), HIV-ISU+ (22.1\%), HIV+ISU- (36.4\%) compared to the HIV-ISU- (16.7\%) and controls (17.9\%).

214 HIV-1 viral copies were higher in HIV+ISU+ (median=344copies $/ \mu$ ) compared to

215 HIV+ISU- (median=150copies/ $\mu$ l) However, these differences were not statistically 216 significant. The rates of viral failure $(\geq 1000$ copies/ $\mu l)$ were pronounced in both groups ( 217 HIV+ISU+, 53.2\% and HIV+ISU- (54.5\%). 
Table 1. Anthropometric measures, CD4 and viral loads.

\begin{tabular}{|c|c|c|c|c|c|c|c|}
\hline & \multicolumn{2}{|c|}{ Non-Injection Substance Users } & \multicolumn{3}{|c|}{ Injection Substance Users } \\
\hline \multicolumn{2}{|r|}{ Characteristics } & $\begin{array}{c}\text { Controls } \\
\mathrm{n}=56\end{array}$ & $\begin{array}{c}\text { HIV-ISU- } \\
n=186\end{array}$ & $\begin{array}{c}\text { HIV+ISU- } \\
\mathbf{n}=\mathbf{3 3}\end{array}$ & $\begin{array}{c}\text { HIV-ISU+ } \\
\text { n=213 }\end{array}$ & HIV+ISU+ n=62 & P-Value \\
\hline 222 & Age, yrs & $26.8(10.3)$ & $31.2(11.9)^{\mathrm{a}}$ & $34.2(14.7)^{\mathrm{a}}$ & $31.7(9.1)^{\mathrm{b}}$ & $30.6(6.3)$ & 0.0047 \\
\hline 223 & Female/male, $(\%)$ & $53.6 / 46.4$ & $55.4 / 44.6$ & $51.5 / 48.5$ & $6.6 / 93.4$ & $50.0 / 50.0$ & $<0.0001$ \\
\hline \multicolumn{8}{|c|}{ Anthropometric } \\
\hline \multirow[t]{2}{*}{224} & Height (metres) & $1.6(1.5-1.8)$ & $1.6(1.4-1.8)$ & $1.6(1.5-1.8)^{\mathrm{a}}$ & $1.7(1.5-1.9)^{\mathrm{c}}$ & $1.7(1.4-1.8)$ & $<0.0001$ \\
\hline & Weight (kg) & $60(44-88)$ & $61(33-98)$ & $52(38-87)^{b, c}$ & $54(40-108)^{c}$ & $54(39-74)^{\mathrm{c}}$ & $<0.0001$ \\
\hline \multicolumn{2}{|c|}{ 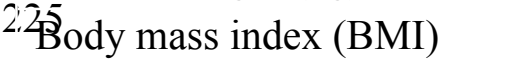 } & $21.4(15.5-34.6)$ & $21.8(12.8-40.0)$ & $18.7(13.1-33.9)^{\mathrm{a}, \mathrm{c}}$ & $18.6(12.1-33.3)^{\mathrm{c}}$ & $18.9(15.2-25.6)^{\mathrm{c}}$ & $<0.0001$ \\
\hline & $\mathrm{BMI}<18.5, \mathrm{n}(\%)$ & $5(8.9)$ & $42(22.6)$ & $16(48.5)$ & $101(47.4)$ & $20(32.3)$ & \\
\hline \multicolumn{2}{|c|}{ CD4 count, cells $/ \mu \mathrm{l}$} & $774(462.0)$ & $859(515)$ & $647(573)$ & 905 (639) & $519(471)$ & $<0.0001$ \\
\hline \multicolumn{2}{|c|}{$2: 27500$ cells/ $\mu 1, \mathrm{n}(\%)$} & $10(17.9)$ & $31(16.7)$ & $12(36.4)$ & $47(22.1)$ & $29(46.8)$ & \\
\hline \multirow{2}{*}{\multicolumn{2}{|c|}{ 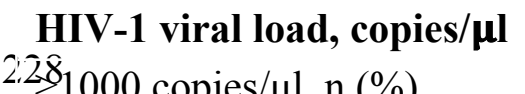 }} & - & - & $150(150-571900)$ & - & $344(150-451300)$ & 0.7556 \\
\hline & & - & - & $18(54.5)$ & - & $33(53.2)$ & \\
\hline
\end{tabular}

229

230 Results are presented as medians (range) or as indicated. HIV, Human Immunodeficiency Virus; HIV+ISU+, HIV-positive injection substance 231 users; HIV-ISU+, HIV-negative, injection substance users; HIV+ISU-, HIV-positive non-injection substance users; HIV-ISU-, HIV-negative 232 non-injection substance users. Chi-square test was used for proportions while the Kruskal-Wallis test used for continuous data followed by duns' 233 posthoc for multiple comparisons. Significant p-values are in bold. ${ }^{a} \mathbf{p}<\mathbf{0 . 0 5}$ : HIV+ISU- vs. controls (age, height, BMI); HIV-ISU- vs. controls 234 (age) and HIV+ISU- vs. HIV-ISU- (BMI); ${ }^{\mathbf{b}} \mathbf{p}<\mathbf{0 . 0 1}$ : HIV-ISU+ vs. HIV+ISU- (age); HIV+ISU- vs HIV-ISU- (weight) and HIV+ISU- vs. 235 controls (weight); ${ }^{\mathbf{c}} \mathbf{p}<\mathbf{0 . 0 0 1}$ : HIV+ISU+ vs. HIV-ISU- (weight, BMI); HIV+ISU+ vs. controls (BMI); HIV-ISU+ vs. HIV-ISU- (height, 236 weight, BMI) and HIV-ISU+ vs. controls (weight, BMI). 


\section{Erythrocyte measures}

238 Erythrocyte measures are summarised in Table 2. The median erythrocyte counts differed 239 across the groups $(\mathrm{p}=0.0029)$ with higher counts in the HIV-ISU+ (median, 4.9 $\times 10^{12} / \mathrm{L}$; $240 \mathrm{IQR}=0.2)$ relative to HIV+ISU- (median, $\left.4.0 \times 10^{12} / \mathrm{L} ; \mathrm{IQR}=1.2 ; \mathrm{p}=0.0078\right)$. Haemoglobin 241 concentration also differed amongst the groups $(p<0.0001)$, and was elevated in the HIV242 ISU+ (median, 12.6g/dL; IQR=2.3) compared to the HIV+ISU- (median, 11.6g/dL; IQR=3.3; $243 \mathrm{p}=0.0077)$. Similarly, HIV+ISU- had lower haemoglobin compared to the HIV-ISU244 (median, 12.8g/dL; IQR=2.5; $\mathrm{p}=0.0003$ ) and controls (median, 13.5g/dL; IQR=2.7; $245 \mathrm{p}<0.0001)$. Moreover, haematocrit was altered across the groups $(\mathrm{p}=0.0025)$ and was raised 246 in HIV-ISU+ (median, 41.8\%; IQR=6.4) relative to HIV+ISU- (median, 38.5\%; IQR=11.7; $247 \mathrm{p}=0.0379$ ) and HIV-ISU- (median, 39.7\%; IQR=7.8; $\mathrm{p}=0.0073$ ).

248 The median mean corpuscular volume (MCV) was not similar across the study groups. The 249 mean corpuscular haemoglobin $(\mathrm{MCH})$ values differed across the study groups $(\mathrm{p}=0.0020)$.

250 Depressed MCH levels were observed in HIV-ISU+ (median, 26.4pg; IQR=3.7) compared to 251 the controls (median, 29.0pg; IQR=52; $\mathrm{p}=0.0006$ ). Meanwhile, the mean corpuscular 252 haemoglobin concentration $(\mathrm{MCHC})$ differed amongst the groups $(\mathrm{p}<0.0001)$ and was low in 253 HIV-ISU+ (median, 31.5g/dL; IQR=4.2) relative to HIV-ISU- (median, 31.9g/dL; IQR=2.7; $254 \mathrm{p}<0.0001$ ) and controls (median, 32.5g/dL; IQR=2.8; $\mathrm{p}=0.0004$ ). The red cell distribution 255 width (RDW) was different across the groups $(\mathrm{p}=0.0036)$ with posr-hoc analysis indicating 256 lower levels in HIV-ISU+ (median,13.5\%; IQR=2.3) in comparison to HIV-ISU- (median, 257 $14.7 \%$;QR=3.2; $\mathrm{p}=0.0029)$. 
Table 2. Erythrocyte measures.

\begin{tabular}{|c|c|c|c|c|c|c|}
\hline \multirow[b]{2}{*}{$\begin{array}{c}\text { Erythrocyte } \\
\text { measures }\end{array}$} & \multirow[b]{2}{*}{$\begin{array}{c}\text { Controls } \\
n=56\end{array}$} & \multicolumn{2}{|c|}{$\begin{array}{c}\text { Non-Injection Substance } \\
\text { Users }\end{array}$} & \multicolumn{2}{|c|}{$\begin{array}{c}\text { Injection Substance } \\
\text { Users }\end{array}$} & \multirow[b]{2}{*}{ P-Value } \\
\hline & & $\begin{array}{c}\text { HIV-ISU- } \\
n=186 \\
\end{array}$ & $\begin{array}{c}\text { HIV+ISU- } \\
\mathbf{n}=\mathbf{3 3}\end{array}$ & $\begin{array}{c}\text { HIV-ISU+ } \\
n=213 \\
\end{array}$ & $\begin{array}{c}\text { HIV }+ \text { ISU } \\
+\mathrm{n}=62 \\
\end{array}$ & \\
\hline $\mathrm{RBC}, \times 10^{12} / \mathrm{L}$ & $4.8(1.0)$ & $4.8(0.9)$ & $4.0(1.2)^{\mathrm{a}}$ & $4.9(0.8)$ & $4.7(0.7)$ & 0.0029 \\
\hline $\mathrm{HGB}, \mathrm{g} / \mathrm{dL}$ & $13.5(2.7)$ & $12.8(2.5)$ & $11.6(3.3)^{\mathrm{a}, \mathrm{c}}$ & $12.6(2.3)$ & $12.5(1.8)$ & $<0.0001$ \\
\hline $\mathrm{HCT}, \%$ & $40.8(6.5)$ & $39.7(7.8)$ & $38.5(11.7)^{\mathrm{a}}$ & $41.8(6.4)$ & $39.9(7.0)$ & 0.0025 \\
\hline $\mathrm{MCV}, \mathrm{fL}$ & $89.8(12.4)$ & $84.9(10.7)^{\mathrm{a}}$ & $86.1(17.3)$ & $85.2(8.8)$ & $85.9(9.5)$ & 0.0726 \\
\hline $\mathrm{MCH}, \mathrm{pg}$ & $29.0(5.2)$ & $27.3(4.4)$ & $27.6(6.2)^{\mathrm{c}}$ & $26.4(3.7)$ & $27.0(4.4)$ & 0.0020 \\
\hline $\mathrm{MCHC}, \mathrm{g} / \mathrm{dL}$ & $32.5(2.8)$ & $31.9(2.7)$ & $31.5(4.2)^{\mathrm{c}}$ & $30.7(3.0)$ & $31.3(2.7)$ & $<0.0001$ \\
\hline RDW,\% & $14.4(2.8)$ & $14.7(3.2)$ & $13.9(2.9)^{b}$ & $13.5(2.3)$ & $14.0(3.0)$ & 0.0036 \\
\hline
\end{tabular}

260 Data shown are medians (IQR). HIV, Human Immunodeficiency Virus; HIV+ISU+, HIV-

261 positive injection substance users; HIV-ISU+, HIV-negative, injection substance users;

262 HIV+ISU-, HIV-positive non-injection substance users; HIV-ISU-, HIV-negative non-

263 injection substance users; RBC, red blood cell; HGB, Haemoglobin; HCT, haematocrit;

$264 \mathrm{MCV}$, mean corpuscular volume; $\mathrm{MCH}$, mean corpuscular haemoglobin; MCHC, mean

265 corpuscular haemoglobin concentration; RDW, red cell distribution width. Erythrocyte

266 measures were compared across the groups using the Kruskal-Wallis test followed by duns

267 posthoc test. Significant p-values are in bold, ap< ${ }^{a} \mathbf{0 . 0 5}$ : HIV-ISU+ vs. HIV+ISU- (RBC, Hgb,

268 HCT); HIV-ISU- vs. controls (MCV). ${ }^{\mathbf{b}} \mathbf{p}<\mathbf{0 . 0 1}$ : HIV-ISU+ vs. HIV-ISU- (RDW). ${ }^{\mathbf{c}} \mathbf{p}<\mathbf{0 . 0 0 1 :}$

269 HIV-ISU+ vs HIV-ISU- (MCHC); HIV-ISU+ vs. Controls (MCH, MCHC); HIV+ISU- vs.

270 HIV-ISU- (Hgb).

\section{Anaemia levels, types and aetiology}

272 The overall rates of anaemia were higher in HIV-positive subjects (ISU, 48.4\% and non-ISU, $27363.6 \%)$ and HIV-negative ISU (56.3\%) relative to the HIV negative non-ISU (39.2\%) and 274 controls (28.6\%) (Fig 1). Most of the anaemia was mild and moderate (HIV-positive ISU, $27556.7 \%$ and $40 \%$, and non-ISU, 33\% and 52.4\%; HIV-negative ISU, $66.7 \%$ and 32.5\%, and 276 non-ISU, $63 \%$ and $28.8 \%$ ), respectively.

277 Fig 1. Anaemia levels across the study groups.

278 Primary axis shows anaemia levels represented by the shaded bars. Secondary axis shows the

279 haemoglobin concentration where the whiskers (-) represent the $25^{\text {th }}$ and 75 th percentiles for 280 haemoglobin values while the dot $(\cdot)$ represent the median haemoglobin value. p-values are 
for the haemoglobin concentration within each anaemia level. HIV-ISU-, HIV negative noninjection substance user; HIV+ISU-, HIV positive non-injection substance users; HIV-ISU+, HIV negative injection substance users; HIV+ISU+, HIV positive injection substance users.

Based on RBC morphology, the most prevalent anaemia was hypochromic and normochromic anaemia: (HIV-positive ISU, 50\% and 46.7\%; and non-ISU, $61.9 \%$ and $38.1 \%$; HIV-negative ISU, $63.3 \%$ and 35\%, and non-ISU 39.7\% and 60.3\%). Hyperchromic anaemia was less common manifesting amongst the HIV+ISU+ $(3.3 \%)$, the HIV-ISU+ (1.7\%) and controls (6.3\%) (Fig 2).

\section{Fig 2. Anaemia types across the study groups.}

Primary axis shows anaemia types represented by the shaded bars. Secondary axis shows the mean corpuscular haemoglobin concentration (MCHC) where the whiskers (-) represent the $25^{\text {th }}$ and 75th percentiles for MCHC while the dot $(\cdot)$ represent the median. p-values are for the MCHC values within each anaemia type. HIV-ISU-, HIV negative non-injection substance user; HIV+ISU-, HIV positive non-injection substance users; HIV-ISU+, HIV negative injection substance users; HIV+ISU+, HIV positive injection substance users

Anaemia due to mixed aetiology was the most prevalent $(49.6 \%)$, followed by chronic inflammation (22.9\%), nutritional deficiency (15.8\%) and blood loss (12.7\%) (Fig 3).

\section{Fig 3. Anaemia aetiology across the study groups.}

Primary axis shows anaemia aetiology frequency as represented by the shaded bars. Secondary axis shows the red cell distribution width (RDW) where the whiskers (-) represent the $25^{\text {th }}$ and 75 th percentiles for RDW while the dot $(\cdot)$ represent the median. p-values are for the RDW values within each aetiology. HIV-ISU-, HIV negative non-injection substance user; HIV+ISU-, HIV positive non-injection substance users; HIV-ISU+, HIV negative injection substance users; HIV+ISU+, HIV positive injection substance users

\section{Association of anaemia with undernutrition, immune suppression and viral failure}

Regression analysis within the HIV+ISU+ and HIV+ISU- indicated that anaemia was neither associated with under-nutrition, immunosuppression or viral failure. However, anaemia was associated with immunosuppression, amongst the HIV-ISU+, $(\mathrm{OR}=3.952, \mathrm{CI}=1.934-8.077$, $\mathrm{p}<0.0001)$ and HIV-ISU- $(\mathrm{OR}=3.630, \mathrm{CI}=1.571-8.390, \mathrm{p}=0.003)$.

\section{Discussion}

Anaemia is characterized by the insufficiency in the number of red blood cells, consequently affecting their oxygen carrying and delivery capacity to tissues (71). Anaemia in Human Immunodeficiency Virus (HIV) infected persons is life threatening as it is associated with enhanced HIV disease progression hence diminished survival (72). Substance use, on the other hand, has been associated with varied haematological derangements including anaemia 
317 (73-75). This cross-sectional study investigated the interplay between substance use, HIV

318 infection and anaemia in Kenyan injection and non-injection substance users not under any

319 active antiretroviral treatment. Erythrocyte indices, anaemia levels, type and aetiology were

320 determined. It was observed that HIV-negative illicit substance users with drug-induced-

321 immune-suppression were thrice as likely to develop anaemia compared to their HIV-positive

322 counterparts. This is important in fostering the treatment and management of illicit substance

323 users while reducing the adverse health consequences of substance use.

324 The overall prevalence of anaemia was highest amongst the HIV-positive non-injection 325 substance users, HIV negative injection substance users and HIV positive injection substance users. Typically, anaemia was more severe in HIV positive substance users compared to HIV negative substance users. It is likely that HIV-infection in substance users aggravates anaemia. HIV has been shown to replicate in other cells of the haematopoietic lineage other than the immune cells thus leading to the haematological derangements, with erythroid dysplasia observed as a common feature upon bone marrow examination of people who are infected with HIV (76-78). The overall prevalence of anaemia amongst the healthy controls $(28.6 \%)$ in the study area of the coastal city of Mombasa Kenya was lower than that of the global prevalence described elsewhere (79), but relatively higher compared to the World 334 Health Organization estimates for the prevalence of anaemia (24.8\%) in the general population of Kenya (80). The controls in this study were recruited from asymptomatic individuals within the community. Thus, it was observed that in as much as individuals within a community would seem healthy due to lack of clinical symptoms, laboratory investigations seem to suggest otherwise. High rates of anaemia in the general population from the coastal city are attributable to the extravagant prevalence of malnutrition, chronic protozoal and helminthic infections (81-83).

341 Generally, anaemia rates were high in the substance-using groups compared to the controls 342 suggesting that illicit substance use is associated with anaemia which is exacerbated by HIV 343 infection. It is possible that drug metabolites negatively influence erythropoietic hormones 344 and may trigger intravascular haemolysis and premature splenic destruction of red blood cells. However, this hypothesis needs to be substantiated with further research on the same. Mild and moderate anaemia were the most prevalent types of anaemia based on haemoglobin concentration (71). Severe anaemia was the least recorded type of anaemia as individuals in this state are either bedridden or comatose. However, we were able to observe few cases of 
individuals with severe anaemia who were neither comatose nor bedridden across all the study groups. A possible explanation is that the anaemia amongst these individuals might have developed over long periods of time providing room for the physiologic compensatory mechanisms to kick in hence allowing greater loss of red blood cell (RBC) mass over time without any obvious clinical symptoms (84).

354 Chronic inflammation was the second most common mechanism associated with anaemia prevailing in injection and non-injection substance users. Therefore, substance use is likely to be associated with inflammation. Khat and alcohol use has been shown to cause intestinal lesions leading to gastritis (85-90). This intestinal inflammation is likely to cause the liver to secrete more of the hormone hepcidin which acts by preventing the body from utilizing stored iron (ferritin) and subduing iron absorption in the duodenum. As a matter of fact, anaemia due to nutritional deficiency was the third most common cause across all the study participants. Nutritional deficiency anaemia is probably due to the low dietary intake of iron, folate and vitamin B12 in the general population and substance-induced damage of the gastrointestinal mucosa within the substance using groups (91). Mal-absorption states in these groups need to be investigated including the production and inhibition of the intrinsic factor, which is important in differentiating the types of nutritional anaemias.

366 Anaemia due to mixed aetiology was the most frequent mechanism across our study participants. However, due to the limited resources and time constraints, we could not perform further investigations to specifically determine the kinetics underlying the mixed aetiology of anaemia. Despite this challenge, reports from our analysis indicated a coexistence of the above mechanisms with other aetiologies whose haematological "blueprints" were suggestive of underlying hemoglobinopathies and thalassemias. However, this claim needs to be substantiated by further investigations. In addition, there were wispy signs indicative of intravascular haemolysis and suppression of erythropoiesis. We speculate that intravascular haemolysis could be attributable to the damping effect where the drug metabolites are adsorbed onto the RBCs which become antigenic resulting in their untimely destruction by the immune and the reticuloendothelial system.

377 Anaemia observed was also classified based on the RBC chromasia as hyperchromic,

378 hypochromic and normochromic. Hypochromic anaemia was the most prevalent type of anaemia accounting for more than $50 \%$ of the anaemia. Hypochromic anaemia was common across all the study groups. Some of the mechanisms driving the existence of hypochromic 
anaemia include iron deficiency, toxic anaemia, sideroblastic anaemia, myelodysplasia, haemolytic thalassemia and megaloblastic anaemia (92). Chronic alcohol users have been shown to present with clinical findings suggestive sideroblastic and megaloblastic anaemia (57). In our study, a nutritional deficiency was the third most common cause of anaemia, which could be attributable to insufficient iron supplementation in the diet. Studies have reported the most common cause of anaemia in resource-limited tropical settings include underlying nutritional deficiencies and endemic parasitic infections (93). Substance addicts have been observed to have altered eating habits such as bypassing meals and fasting in order to prolong the effects of the drugs (94). These addicts usually have limited finances which are mainly spent on sustaining their drug habits hence have a lower dietary intake of fruits, vegetables and other animal products. As such, they are prone to numerous vitamin deficiencies, some of which are necessary for the synthesis of haemoglobin (such as vitamin B12, folate) while others aid in the absorption of iron from the intestines (e.g. vitamin C). Microcytic hypochromic anaemia was the second most common type of hypochromic anaemia amongst the study participants and has been associated with chronic inflammation and thalassemias (84). Consistent with our findings, previous studies showed that the use of illicit injection substance was associated with normocytic hypochromic anaemia whose main aetiology is the iron deficiency (95). However, the physiological and biochemical mechanisms behind the iron deficiency have not been demonstrated warranting further laboratory investigations to delineate between real nutritional deficiency and iron distribution disorders.

Normochromic anaemia was the second most prevalent type of anaemia. Normochromic anaemia has been associated with a number of mechanisms such as short-term blood loss with adequate physiologic reserves, accelerated red blood cell turnover and suppression of red blood cell production when there is adequate iron intake (92). Normocytic normochromic anaemia was most prevalent in HIV-negative non-injection substance users (37\%); HIV infected non-injection drug users (33.3\%) and HIV infected injection drug users (30\%). Since normocytic normochromic anaemia is more predominant in HIV infected individuals, it is concluded that HIV disease accelerates normocytic normochromic anaemia. The aetiology of normocytic normochromic anaemia has been described elsewhere (96) to be as a result of

411 chronic disease, destruction of red blood cells and the disappearance of erythrocyte 412 precursors from the bone marrow; factors which have been well recorded in HIV disease 413 progression $(7,97-102)$. 
414 Haemoglobin levels were significantly lower in HIV positive non-injection drug users 415 compared to controls, HIV naïve non-injection drug users and HIV naïve injection drug 416 users. This observation proposes that HIV infection may be the culprit resulting in reduced 417 haemoglobin. This is backed up by a study which revealed that advanced HIV progression is 418 marked by a reduction in haemoglobin (97) due to alterations in cytokine production 419 affecting other homeostatic processes such as hematopoiesis; autolysis and Vitamin-B12 420 deficiency due to impaired absorption (103).

421 Results from this study show a significant decline in erythrocyte counts in HIV infected non422 injection substance users compared to HIV-negative injection substance users. HIV-negative 423 non-ISU exhibit higher erythrocyte levels suggesting that HIV infection may play a role in erythrocyte depression. This finding is similar to a study that investigated the role of HIV in anaemia (72,101). Different mechanisms have been conjectured by which HIV suppress RBC counts and they include marred division and endurance of hematopoietic progenitor cells $(98,99)$, aberrant cytokine production such as erythropoietin by stromal cells and autoimmune responses resulting in the untimely destruction of red blood cells in the spleen and by autoantibodies (101).

430 On the other hand, the relatively normal erythrocyte counts in HIV-infected injection substance users similar to that of the controls suggest that injection substance use seem to ameliorate RBC populations in HIV infected individuals. This finding is similar to a different study where opium and heroin-dependent individuals did not exhibit significant differences in their erythrocyte populations compared to the healthy groups (43). However; despite the fact that $\mathrm{RBC}$ population is not significantly altered in number; erythrocyte function is altered as shown in a different study (104) where the red cell immune-adherence function was significantly decreased in heroin users. Therefore, it would be of great interest to investigate erythrocyte function amongst these groups.

439 Immune status was classified based on the Centers for Disease control guidelines (105). 440 Results from this study show that immune suppression was marked in HIV positive substance users. This is attributable to the fact that HIV virus replicates in immune cells causing their premature death upon pyroptosis $(37,44,101)$. Immunosuppression was also observed in illicit

443 substance users who were HIV negative. Studies conducted on non-human primates have 444 demonstrated the immunosuppressive effects of morphine on the immune cells (106). In the aforementioned study, T-cell activation in non-human primates was significantly decreased 
upon morphine administration with negligible changes in T-cell, neutrophil and natural killer cell counts. Proteomic analysis in this study showed a significant decrease in the protein Ki67+. The Ki-67+ is an important signalling molecule that aids in cellular proliferation $(107,108)$. It would be of very much interest to investigate the proteome and metabolome within our study population to better understand the alterations in their physiological processes.

The regression analysis outcomes of this study suggest that HIV negative substance users with drug-induced immunosuppression are likely to develop anaemia compared to the HIV positive substance users. We speculate that this observed association may be as a result of deficiencies in one or more micronutrients other than iron such as copper and zinc that may be critical for both immune function and production of haemoglobin by modulating enzymes associated with these processes. However, this assertion needs to be tested and substantiated by further studies.

\section{Conclusion and recommendations}

Haematological, immune and nutritional parameters are influenced by infections with HIV and substance use. Combinations of these two factors exacerbate anaemia and other haematological anomalies. Haemoglobin levels and red blood cell indices are significantly altered in HIV infected substance users compared to HIV negative substance users. Examination of the bone marrow for erythroblasts and reticulocyte counts are warranted to determine the effect of substance use and HIV on haematopoiesis in these individuals. In addition, there is the need for further biochemical tests such as serum iron, ferritin, total iron binding capacity (TIBC), transferrin, folate, cobalamin, vitamin-C bilirubin and haptoglobin concentration, including testing for liver enzymes, cytokines and kidney function tests to examine the rate of RBC turnover in these individuals.

\section{Acknowledgements}

We thank the study participants for making this study possible. We are grateful to the management and staff of the Bomu Hospital for their support during the study. This study was supported, in part, by the Kenya National Commission for Science, Technology and Innovation [NCST/5/003/065] grants to TW and VB. 


\section{References}

477 1. UNAIDS. Fact sheet 2015 | UNAIDS [Internet]. Fact Sheet. 2015 [cited 2016 May

478

479

480

481

482

483

484

485

486

487

488

489

490

491

492

493

494

495

496

497

498

499

500

501

502

503

504

505

506

507

508

509

510

511 23]. $\quad$ p. 1-8. Available from: http://www.unaids.org/en/resources/campaigns/HowAIDSchangedeverything/factsheet 2. CDC. HIV/AIDS [Internet]. 2015 [cited 2016 May 19]. Available from: http://www.cdc.gov/hiv/basics/transmission.html

3. Budambula V, Musumba FO, Webale MK, Kahiga TM, Owuor FO, Sowayi GA, et al. HIV-1 protease inhibitor drug resistance in Kenyan antiretroviral treatment-naive and experienced injection drug users and non-drug users HIV - 1 protease inhibitor drug resistance in Kenyan antiretroviral treatment-naive and - experienced injection d. AIDS Res Ther [Internet]. 2015;12(27):1-10. Available from: https://www.researchgate.net/publication/281097635

4. Ndombi EM, Budambula V, Webale MK, Musumba FO, Wesongah JO, Mibei E, et al. Serum adiponectin in HIV-1 and hepatitis $\mathrm{C}$ virus mono- and co-infected Kenyan injection drug users Serum adiponectin in HIV-1 and hepatitis C virus mono- and coinfected Kenyan injection drug users. Endocr Connect [Internet]. 2015;4(AUGUST):223-232. Available from: https://www.researchgate.net/publication/281304382

5. Were T, Wesongah JO, Munde E, Ouma C, Kahiga TM, Ongecha-owuor F. R Clinical chemistry profiles in injection heroin users from Coastal Region, Kenya Clinical chemistry profiles in injection heroin users from Coastal Region, Kenya. BMC Clin Pathol. 2014;14(32):1-9.

6. Shaviya N, Budambula V, Webale MK, Were T. Circulating Interferon-Gamma Levels Are Associated with Low Body Weight in Newly Diagnosed Kenyan Non-Substance Using Tuberculosis Individuals Circulating Interferon-Gamma Levels Are Associated with Low Body Weight in Newly Diagnosed Kenyan Non-Substance. 2016;(March).

7. Lucas GM, Griswold M, Gebo KA, Keruly J, Chaisson RE, Moore RD. Illicit drug use and HIV-1 disease progression: A longitudinal study in the era of highly active antiretroviral therapy. Am J Epidemiol. 2006;163(5):412-20.

8. Hile SJ, Feldman MB, Alexy ER, Irvine MK. Recent Tobacco Smoking is Associated with Poor HIV Medical Outcomes Among HIV-Infected Individuals in New York. AIDS Behav [Internet]. 2016;17-21. Available from: http://link.springer.com/10.1007/s10461-015-1273-x

9. Weber R, Huber M, Battegay M, Stähelin C, Castro Batanjer E, Calmy A, et al. Influence of noninjecting and injecting drug use on mortality, retention in the cohort, and antiretroviral therapy, in participants in the Swiss HIV Cohort Study. HIV Med. 2015;16(3):137-51.

10. Tun W, Sheehy M, Broz D, Okal J, Muraguri N, Raymond HF, et al. HIV and STI Prevalence and Injection Behaviors Among People Who Inject Drugs in Nairobi: Results from a 2011 Bio-behavioral Study Using Respondent-Driven Sampling. AIDS Behav. 2015;19(1):24-35.

11. Qian H, Stinnette SE, Rebeiro PF, Kipp A, Bryan E, Samenow CP, et al. The Relationship Between Injection and Non-injection Drug Use and HIV Disease Progression. J Subst Abuse Treat. 2012;41(1):14-20.

12. Jennifer E, Cheng D, Evgeny K, Carly B, Emily Q, Walley AY, et al. Heroin Use and HIV Disease Progression: results from a Pilot Study of a Russian Cohort. AIDS Behav. 2015;19(6):1089-97.

13. Baum M, Rafie C, Lai S, Sales S, Page B, Campa A. Crack Cocaine Use Accelerates HIV Disease Progression in a Cohort of HIV positive Drug Users. J Acquir Immune 
Defic Syndr. 2009;50:93-9.

14. Cook J, Brook-Miller J, Cohen M. Crack Cocaine, Disease Progression and Mortality in a Multicenter Cohort of HIV-1 positive Women. AIDS. 2008;22:1355-63.

15. Rafie C, Campa A, Smith S, Huffman F, Newman F, Baum MK. Cocaine Reduces Thymic Endocrine Function: Another Mechanism for Accelerated HIV Disease Progression. AIDS Res Hum Retroviruses [Internet]. 2011 [cited 2017 Apr 16];27(8):815-22. Available from: https://www.ncbi.nlm.nih.gov/pmc/articles/PMC3180730/pdf/aid.2010.0086.pdf

16. Kapadia F, Vlahov D, Donahoe RM, Friedland G. The Role of Substance Abuse in HIV Disease Progression: Reconciling Differences from Laboratory and Epidemiologic Investigations. Clin Infect Dis. 2005;41(August):1027-34.

17. Langford SE, Ananworanich J, Cooper DA. AIDS Research and Therapy Predictors of disease progression in HIV infection : a review. 2007;14:1-14.

18. Napuri J, Pilakka-kanthikeel S, Raymond A, Agudelo M, Yndart-arias A, Saxena SK, et al. Cocaine Enhances HIV-1 Infectivity in Monocyte-Derived Dendritic Cells by Suppressing microRNA-155. 2013;8(12):1-9.

19. Meijerink H, Wisaksana R, Iskandar S, Heijer M Den, Ven AJAM Van Der, Alisjahbana $\mathrm{B}$, et al. Injecting drug use is associated with a more rapid CD4 cell decline among treatment-naive HIV-positive patients in Indonesia. J Int AIDS Soc. 2014;17(18844):1-7.

20. Poundstone KE, Chaisson RE, Moore RD. Differences in HIV disease progression by injection drug use and by sex in the era of highly active antiretroviral therapy. 2016;(December 2000).

21. UNODC UNO on D and C. Women and Drugs: Drug Use, Drug Supply and their Consequences [Internet]. Booklet 5. Vienna, Austria: United Nations; 2018. 1-42 p. Available from: https://www.unodc.org/wdr2018

22. UNODC UNO on D and C. Drugs and Age: Drugs and Associated Issues Among Young People and Older People [Internet]. Vienna, Austria: United Nations; 2018. 162 p. Available from: https://www.unodc.org/wdr2018

23. UNODC UNO on D and C. Analysis of Drug Markets: Opiates, Cocaine, Cannabis, Synthetic Drugs [Internet]. Booklet 3. Vienna, Austria: United Nations; 2018. 1-76 p. Available from: https://www.unodc.org/wdr2018

24. UNODC UNO on D and C. Global Overview of Drug Demand and Supply: Latest trends, cross-cutting issues [Internet]. Booklet 2. Vienna, Austria: United Nations; 2018. 1-64 p. Available from: https://www.unodc.org/wdr2018

25. UNODC UNO on D and C. Executive Summary, Conclusions and Policy Implications [Internet]. Booklet 1. Vienna, Austria: United Nations; 2018. 1-34 p. Available from: https://www.unodc.org/wdr2018

26. Beckerleg S, Telfer M, Hundt GL. The rise of injecting drug use in East Africa: a case study from Kenya. Harm Reduct J. 2005;2(12):1-9.

27. Were T, Wesongah JO, Munde E, Ouma C, Kahiga TM, Ongecha-owuor F, et al. Clinical chemistry profiles in injection heroin users from Coastal Region, Kenya. BMC Clin Pathol. 2014;14(1):1-9.

28. UNODC. World Drug Report [Internet]. Igarss 2014. New York; 2015. 1-5 p. Available from: www.unodc.org

29. UNODC. World Drug Report 2014. United Nations publication. 2014. Sales No. E.14.XI.7.

30. Budambula V, Matoka C, Ouma J, Ahmed AA, Otieno MF, Were T. Sociodemographic and sexual practices associated with HIV infection in Kenyan injection and non-injection drug users. BMC Public Health. 2018;18(193):1-9. 
31. Aceijas C, Stimson G, Hickman M, Rhodes T. Global Overview of Injecting Drug Use and HIV Infection among Injecting Drug Users. Aids [Internet]. 2004;18(17):2295303. Available from: https://scholar.google.com/scholar?cluster=2178344871507473784\&hl=en\&oi=schola $\mathrm{rr} \# 0$

32. Nieburg P, Carty L. HIV Prevention among Injection Drug Users in Kenya and Tanzania HIV Prevention among Injection Drug Users in Kenya and Tanzania. 2011;(April).

33. Musyoki H. An Overview of Programs for People who Inject Drugs. In: MARPS and Vulnerable Groups Program. Nairobi; 2012.

34. NACADA. Rapid Situation Assessment of the Status of Drug and Substance Abuse. 2012;

35. Phelan M, Nougier M, September JB $\Delta$. IDPC Briefing Paper HIV prevention among people who use drugs in East Africa. 2013;(September):1-16.

36. Mathers BM, Degenhardt L, Phillips B, Wiessing L, Hickman M, Strathdee SA, et al. Global epidemiology of injecting drug use and HIV among people who inject drugs : a systematic review. 2008;6736(8):1-13.

37. Aceijas C, Stimson G V, Hickman M, Rhodes T. Global overview of injecting drug use and HIV infection among injecting drug users on behalf of the United Nations Reference Group on HIV / AIDS Prevention and Care among IDU in Developing and Transitional. 2004;(April).

38. National T, Against C, Abuse D. 'Promotion of Evidence-Based Campaign' National Alcohol and Drug Abuse Research Workshop 2011 Report Held at the Kenya Institute of Administration. 2011;(March).

39. Kibaru EG, Nduati R, Wamalwa D, Kariuki N. Impact of highly active antiretroviral therapy on hematological indices among HIV-1 infected children at Kenyatta National Hospital-Kenya: retrospective study. AIDS Res Ther [Internet]. 2015;12(1):26. Available from: http://www.aidsrestherapy.com/content/12/1/26

40. Kibaru EG, Nduati R, Wamalwa D, Kariuki N. Baseline Hematological Indices among HIV-1 Infected Children at Kenyatta National Hospital. Int J Nov Res Health Nurs. 2014;1(1):21-6.

41. Jemikalajah JD, Okogun GA. Hematological indices in human immunodeficiency virus and pulmonary tuberculosis infections in parts of Delta State, Nigeria. Saudi Med J. 2009;30(2):253-6.

42. Mgogwe J, Semvua H, Msangi R, Mataro C, Kajeguka D, Chilongola J. The evolution of haematological and biochemical indices in HIV patients during a six-month treatment period. Afr Health Sci. 2012;12(1):1-6.

43. Haghpanah T, Afarinesh M, Divsalar KM. A Review on Hematological Factors in Opioid-Dependent People (Opium and Heroin) after the Withdrawal Period. Addict Heal Winter Spring [Internet]. 2010 [cited 2017 Apr 16];2(9). Available from: https://www.ncbi.nlm.nih.gov/pmc/articles/PMC3905505/pdf/AHJ-02-009.pdf

44. Enawgaw B, Alem M, Addis Z, Melku M. Determination of hematological and immunological parameters among HIV positive patients taking highly active antiretroviral treatment and treatment naïve in the antiretroviral therapy clinic of Gondar University Hospital, Gondar, Northwest Ethiopia: a com. BMC Hematol [Internet]. 2014;14(1):8. Available from: http:/www.pubmedcentral.nih.gov/articlerender.fcgi?artid=3994311\&tool=pmcentrez \&rendertype $=$ abstract

45. Parinitha SS, Kulkarni MH. Haematological changes in HIV infection with correlation to CD4 cell count. Australas Med J. 2012;5(3):157-62.

46. Munyazesa E, Emile I, Mutimura E, Hoover DR, Shi Q, McGinn AP, et al. 
Assessment of haematological parameters in HIV-infected and uninfected Rwandan women: a cross-sectional study. BMJ Open [Internet]. 2012;2(6):1-8. Available from: http://www.pubmedcentral.nih.gov/articlerender.fcgi?artid=3533001\&tool=pmcentrez \&rendertype $=$ abstract

47. Dikshit B, Wanchu A, Sachdeva RK, Sharma A, Das R. Profile of hematological abnormalities of Indian HIV infected individuals. BMC Blood Disord [Internet]. 2009;9(1):5. Available from: http://www.biomedcentral.com/1471-2326/9/5

48. Ogba OM, Abia-Bassey LN, Epoke J, Mandor BI, Akpotuzor J, Iwatt G, et al. Haematological Profile of HIV Infected Patients with Opportunistic Respiratory Mycoses in Relation to Immune Status - A Hospital-Based Cohort from Calabar, Nigeria. Trop Med Surg. 2013;1(3):1-9.

49. Menezes D, Cunha G, Santis D, Crivelenti F, Amorim R, Zomer R, et al. Hematological particularities and co-infections in injected drug users with AIDS. Brazillian J Infect Dis. 2013;7(6):654-6.

50. Denue B a, Gashau W, Bello HS, Kida IM, Bakki B, Ajayi B. Relation between some haematological abnormalities, degree of immunosuppression and viral load in treatment-naïve HIV-infected patients. East Mediterr Heal J. 2013;19(4):1-7.

51. Kyeyune R, Saathoff E, Ezeamama AE, Löscher T, Fawzi W, Guwatudde D. Prevalence and correlates of cytopenias in HIV-infected adults initiating highly active antiretroviral therapy in Uganda. 2014;14(496):1-10. Available from: http://www.biomedcentral.com/1471-2334/14/496

52. Webale MK, Kilongosi MW, Budambula V, Lihana R, Musumba FO, Nyamache AK, et al. Hepatitis B virus sero-profiles and genotypes in HIV-1 infected and uninfected injection and Non-injection drug users from coastal Kenya. BMC Infect Dis. 2015 Jul; 15:299.

53. WHO WHO. Table 7.15 WHO definitions of clinical, immunological and virological failure for the decisions to swith $\backslash c h$ to ART treatment. 2016;

54. Menezes D, Cunha G, Santis D, Crivelenti F, Amorim R, Zomer R, et al. Original article Hematological particularities and co-infections in injected drug users with AIDS. 2013;7(6):654-6.

55. Kouros D, Sc M, Tahereh H, Sc M, Sc M. Opium and Heroin Alter Biochemical Parameters of Human's Serum. Am J Drug Alcohol Abuse. 2010;135-9.

56. Mckallip RJ, Lombard C, Fisher M, Martin BR, Ryu S, Grant S, et al. Targeting CB2 cannabinoid receptors as a novel therapy to treat malignant lymphoblastic disease. Blood J. 2002;100(2):627-35.

57. Ballard HAS. The Hematological Complications of Alcoholism. Alcohol Health Res World [Internet]. 1997;21(1):42-52. Available from: http://www.niaaa.nih.gov

58. Aleryani SL, Aleryani RA, Al-akwa AA. Khat a drug of abuse : roles of free radicals and antioxidants $\$$. Drug Test Anal. 2011;3(September 2010):548-51.

59. WHO WHO. Guideline on When to Start AntiRetroviral Therapy and on Pre-Exposure Prophylaxis for HIV [Internet]. 2015 [cited 2016 May 30]. p. 1-78. Available from: http://apps.who.int/iris/bitstream/10665/186275/1/9789241509565_eng.pdf

60. Buechler C, Schaffler A, Johann M, Neumeier M, Kohl P, Weiss T, et al. Elevated Adiponectin Serum Levels in Patients with Chronic Alcohol Abuse Rapidly Decline During Alcohol Withdrawal. J Gastroenterol Hepatol. 2009;24:558-63.

61. Vajpayee M, Kaushik S. CDC staging based on absolute CD 4 count and CD 4 percentage in an HIV- 1 -infected Indian population: treatment implications. 2005;485-90.

62. CDC C for DC. 1997 Revised Guidelines for Performing CD4+ T-cell Determinations in Persons Infected with Human Immunodeficiency Virus (HIV) [Internet]. Vol. 46. 
1997 [cited 2017 Sep 30 Available from: https://www.cdc.gov/mmwr/PDF/rr/rr4602.pdf

63. Yu LYMEE, Easterbrook PJ, Marshall TOM. Relationship between CD4 Count and CD4 \% in HIV-Infected People. 1997;26(6):1367-72.

64. Parinitha SS, Kulkarni MH, College SDM. Haematological changes in HIV infection with correlation to CD4 cell count What this study adds : 2012;157-62.

65. Kranzer K, Lawn SD, Johnson LF, Bekker L-G, Wood R. Community viral load and CD4 count distribution among people living with HIV in a South African Township: implications for treatment as prevention. J Acquir Immune Defic Syndr [Internet]. 2013;63(4):498-505. Available from: /pmc/articles/PMC4233323/?report=abstract

66. Dikshit B, Wanchu A, Sachdeva RK, Sharma A, Das R. Profile of hematological abnormalities of Indian HIV infected individuals. BMC Blood Disord. 2009;9(5):1-6.

67. NIH NI of H. Protecting Human Research Participants [Internet]. 2011. 1-109 p. Available from: http://phrp.nihtraining.com/

68. CDC C for DC. Anthropometry Procedures Manual [Internet]. National Health and Nutrition Examination Survey (NHANES). 2007 [cited 2016 May 26]. 1-105 p. Available from: http://www.cdc.gov/nchs/data/nhanes/nhanes_07_08/manual_an.pdf

69. CDC C for DC. 1993 Revised Classification System for HIV Infection and Expanded Surveillance Case Definition for Aids Among Adolescents and Adults [Internet]. Recommendations and Reports. 1992 [cited 2016 Jun 20]. p. 1-15. Available from: https://www.cdc.gov/mmwr/preview/mmwrhtml/00018871.htm

70. World Health Organization W. Definitions of clinical, immunological and virological failure for the decision to switch ART regimens. 2013;15. Available from: http://www.who.int/hiv/pub/guidelines/arv2013/art/WHO_CG_table_7.15.pdf

71. WHO WHO. Haemoglobin concentrations for the diagnosis of anaemia and assessment of severity [Internet]. 2011. Available from: http:/www.who.int/vmnis/indicators/haemoglobin. pdf

72. Volberding PA, Levine AM, Dieterich D, Mildvan D, Mitsuyasu R, Saag M. Anemia in HIV infection: clinical impact and evidence-based management strategies. Clin Infect Dis. 2004;38(10):1454-63.

73. Richards JR, Farias VF, Clingan CS. Association of Leukocytosis with Amphetamine and Cocaine Use. 2014;2014(January 2009).

74. Dangana A, Nasir IA, Medugu JT, Emeribe AU. Hematological Changes Associated with Illicit Drug Abuse in A City of Northern Nigeria. Int J Hematol Res. 2016;2(3):112.

75. Kalant H. Opium revisited : a brief review of its nature, composition, non-medical use and relative risks ${ }^{\wedge}$. Addiction. 1997;92(September 1996):267-77.

76. Leguit RJ, Tweel JG Van Den. The pathology of bone marrow failure. Histopathology. 2010;57:655-70.

77. Tripathi AK, Misra R, Kalra P, Gupta N, Ahmad R. Bone marrow abnormalities in HIV disease. J Assoc Physicians India. 2005;(September).

78. Dhurve SA, Dhurve AS. Bone Marrow Abnormalities in HIV Disease. Mediterr J Hematol Infect Dis. 2013;5-10.

79. Kassebaum NJ, Jasrasaria R, Naghavi M, Wulf SK, Johns N, Lozano R. A systematic analysis of global anemia burden from 1990 to 2010. Blood. 2014;123(5):615-24.

80. WHO WHO. The global burden of alcohol, smoking and illicit substance use. WHO. 2010;

81. Brooker S, Peshu N, Warn P, Mosobo M, Guyatt H, March K. The Epidemiology of Hookworm Infection and its Contribution to Anemia among Pre-School Children on the Kenya Coast. Tran Sahar Res Trop Med Hyg. 1999;93:240-6. 
82. Leenstra T, Kariuki S, Kurtis J, Oloo A, Kager P, Ter Kuile F. Prevalence and severity of anemia and iron deficiency: cross-sectional studies in adolescent schoolgirls in western Kenya. Eur J Clin Nutr [Internet]. 2004 [cited 2017 Apr 16];58:681-91. Available from: https://www.nature.com/ejcn/journal/v58/n4/pdf/1601865a.pdf

83. Shulman CE, Graham WJ, Jilo H, Lowe BS, New L, Obiero J, et al. Malaria is an important cause of anaemia in primigravidae: evidence from a district hospital in coastal Kenya. Trans R Soc Trop Med Hyg [Internet]. 1996 Sep [cited 2017 Apr 16];90(5):535-9. Available from: https://academic.oup.com/trstmh/articlelookup/doi/10.1016/S0035-9203(96)90312-0

84. Uthman E. Understanding Anemia. University Press of Mississippi; 1998.

85. Nigussie $T$, Gobena $T$, Mossie A. ASSOCIATION BETWEEN CHEWING AND GASTROINTESTINAL DISORDERS : A CROSS-SECTIONAL STUDY. Ethiop J Heal Sci. 2013;23(2):123-30.

86. Hassan M, Mohamed K, Zipporah N, Hudson L. KHAT ( CATHA EDULIS ) USE IS ASSOCIATED WITH THE DEVELOPMENT OF GASTRITIS AMONG ADULTS IN NAIROBI COUNTY , KENYA. East African medical J. 2014;91(6):191-201.

87. Rajendram R, Preedy R. Effect of Alcohol Consumption on the Gut. Digestive Dis. 2005;23:214-21.

88. Bujanda L, Ph D. The Effects of Alcohol Consumption Upon the Gastrointestinal Tract. Am J Gastroenterol. 2000;95(12):3374-82.

89. Stermer E. Alcohol Consumption on the Gastrointestinal Tract. IMAJ. 2002;4(March).

90. Bode C, Bode JC. Alcohol's role in gastrointestinal tract disorders. Alcohol Health Res World [Internet]. 1997;21(1):76-83. Available from: https://pubs.niaaa.nih.gov/publications/arh21-1/76.pdf

91. National Heart Lung and Blood Institute N. Iron-Deficiency Anemia [Internet]. [cited 2018 Mar 29]. Available from: https://www.nhlbi.nih.gov/health-topics/irondeficiency-anemia

92. Theml H, Diem H, Haferlach T. Color Atlas of Hematology: Practical Microscopic and Clinical Diagnosis. 2nd revise. Stuttgart: Thieme; 2004. 127-170 p.

93. Odhiambo C, Zeh C, Ondoa P, Omolo P, Akoth B, Weidle P, et al. Anemia and Red Blood Cell Abnormalities in HIV-Infected and HIV-Exposed Breastfed Infants : A Secondary Analysis of the Kisumu Breastfeeding Study. PLoS One. 2015;10(11):1-14.

94. Strike C, Rudzinski K, Patterson J, Millson M. Frequent food insecurity among injection drug users: correlates and concerns. BMC Public Health [Internet]. 2012;12(1):1-9. Available from: BMC Public Health

95. Dancheck B, Tang AM, Thomas AM, Smit E, Vlahov D, Semba RD. Injection drug use is an independent risk factor for iron deficiency and iron deficiency anemia among HIV-seropositive and HIV-seronegative women. J Acquir Immune Defic Syndr [Internet]. 2005 Oct 1 [cited 2017 Apr 16];40(2):198-201. Available from: http://www.ncbi.nlm.nih.gov/pubmed/16186738

96. Weatherall DJ. Normochromic, normocytic anaemia. In: Oxford Textbook of Medicine [Internet]. Oxford University Press; 2010 [cited 2017 Apr 16]. p. 4401-2. Available from: http://oxfordmedicine.com/view/10.1093/med/9780199204854.001.1/med9780199204854-chapter-220505

97. Obirikorang C, Yeboah FA. Blood haemoglobin measurement as a predictive indicator for the progression of HIV/AIDS in resource-limited setting. J Biomed Sci [Internet]. 2009 [cited 2017 Apr 16];6(102):1-7. Available from: https://www.ncbi.nlm.nih.gov/pmc/articles/PMC2783029/pdf/1423-0127-16-102.pdf

98. Borderi M, Gibellini D, Vescini F, De Crignis E, Cimatti L, Biagetti C, et al. Metabolic bone disease in HIV infection. 2009 [cited 2017 Apr 16]; Available from: 
https://www.unmc.edu/media/hiv/Metabolic Bone Disease.pdf

99. Saccomanno MF, Ammassari A. Bone disease in HIV infection. Clin Cases Miner Bone Metab [Internet]. 2011 Jan [cited 2017 Apr 16];8(1):33-6. Available from: http://www.ncbi.nlm.nih.gov/pubmed/22461801

100. Hambleton J. Hematologic complications of HIV infection. Oncology (Williston Park) [Internet]. 1996 May [cited 2017 Apr 16];10(5):671-80. Available from: http://www.ncbi.nlm.nih.gov/pubmed/8738824

101. Gibellini D, Clò A, Morini S, Miserocchi A, Ponti C, Re MC. Effects of human immunodeficiency virus on the erythrocyte and megakaryocyte lineages. World J Virol May World J Virol [Internet]. 2013 [cited 2017 Apr 16];12(22):91-101. Available from: http://www.wjgnet.com/esps/

102. Mientjes GH, Van Ameijden EJ, Weigel HM, Van den Hoek JA, Coutinho RA. Clinical symptoms associated with seroconversion for HIV-1 among misusers of intravenous drugs: comparison with homosexual seroconverters and infected and noninfected intravenous drug misusers. Br Med J. 1993;306:371-3.

103. Remacha AF, Riera A, Cadafalch J, Gimferrer E. Vitamin B-12 abnormalities in HIVinfected patients. Eur J Haematol [Internet]. 1991 Jul [cited 2017 Apr 16];47(1):60-4. Available from: http://www.ncbi.nlm.nih.gov/pubmed/1868915

104. Xu SW, Song DP, Li H. The effect of heroin on red cell immunoadherence function of human body]. Zhonghua Nei Ke Za Zhi [Internet]. 1993 [cited 2017 Apr 16];807-9. Available from: http://pesquisa.bvsalud.org/oncologiauy/resource/en/mdl-8033655

105. Education A, Centers T, Coordinating N, Ncrc A. HIV Classification : CDC and WHO Staging Systems [ 1 ] Publish Date : S : Subjective O : Objective A : Assessment P : Plan CDC Classification System for HIV Infection. 2014;

106. Brown JN, Ortiz GM, Angel TE, Jacobs JM, Gritsenko M, Chan EY, et al. Morphine Produces Immunosuppressive Effects in Nonhuman Primates at the Proteomic and Cellular Levels * $\square$. Mol Cell Proteomics. 2012;11(9):605-18.

107. Inwald EC, Klinkhammer-Schalke M, Hofstädter F, Zeman F, Koller M, Gerstenhauer $\mathrm{M}$, et al. Ki-67 is a prognostic parameter in breast cancer patients: Results of a large population-based cohort of a cancer registry. Breast Cancer Res Treat. 2013;139(2):539-52.

108. Li LTAO, Jiang G, Chen Q, Zheng JUNN. Ki67 is a promising molecular target in the diagnosis of cancer ( Review ). 2015;1566-72. 


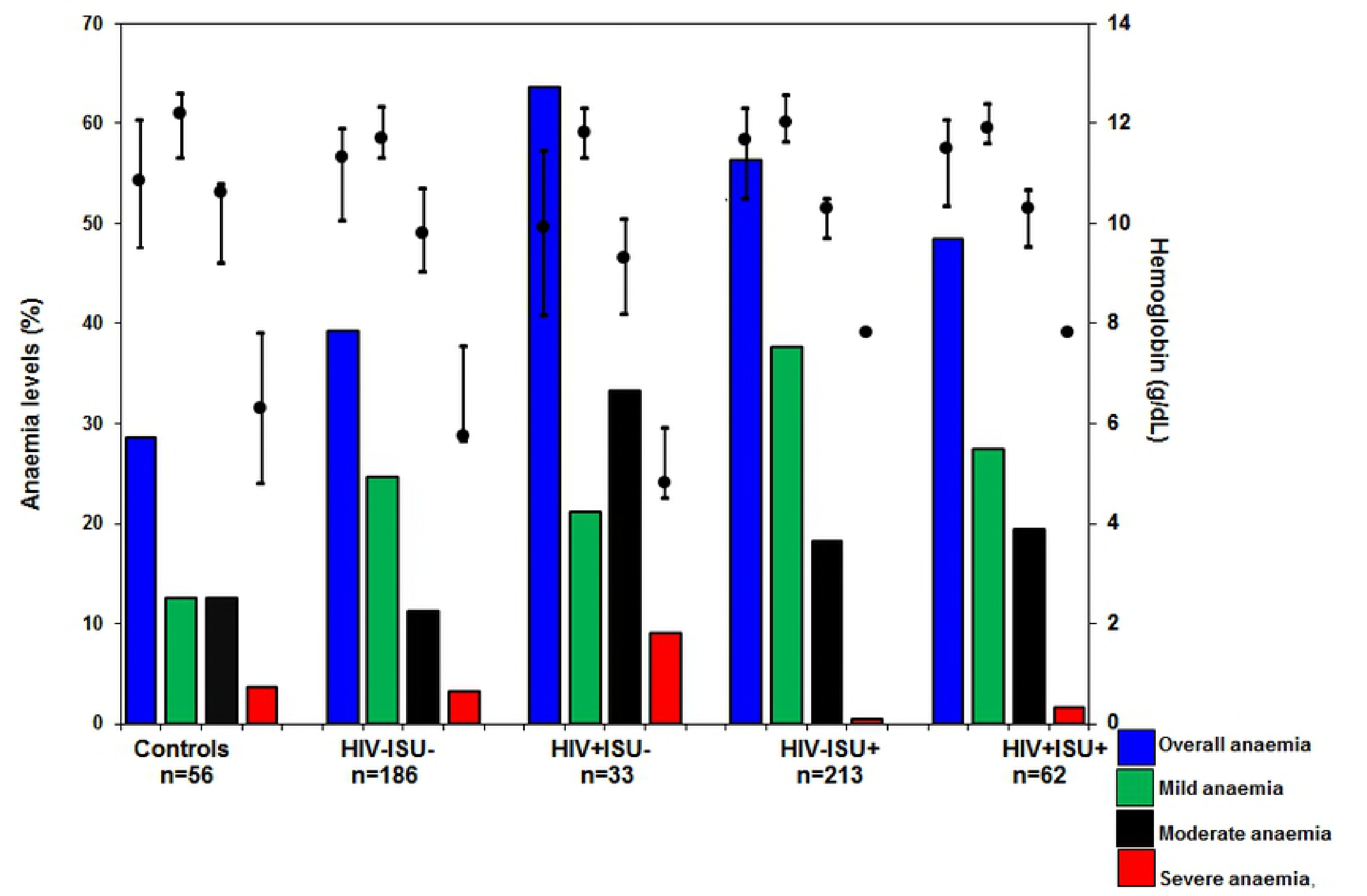




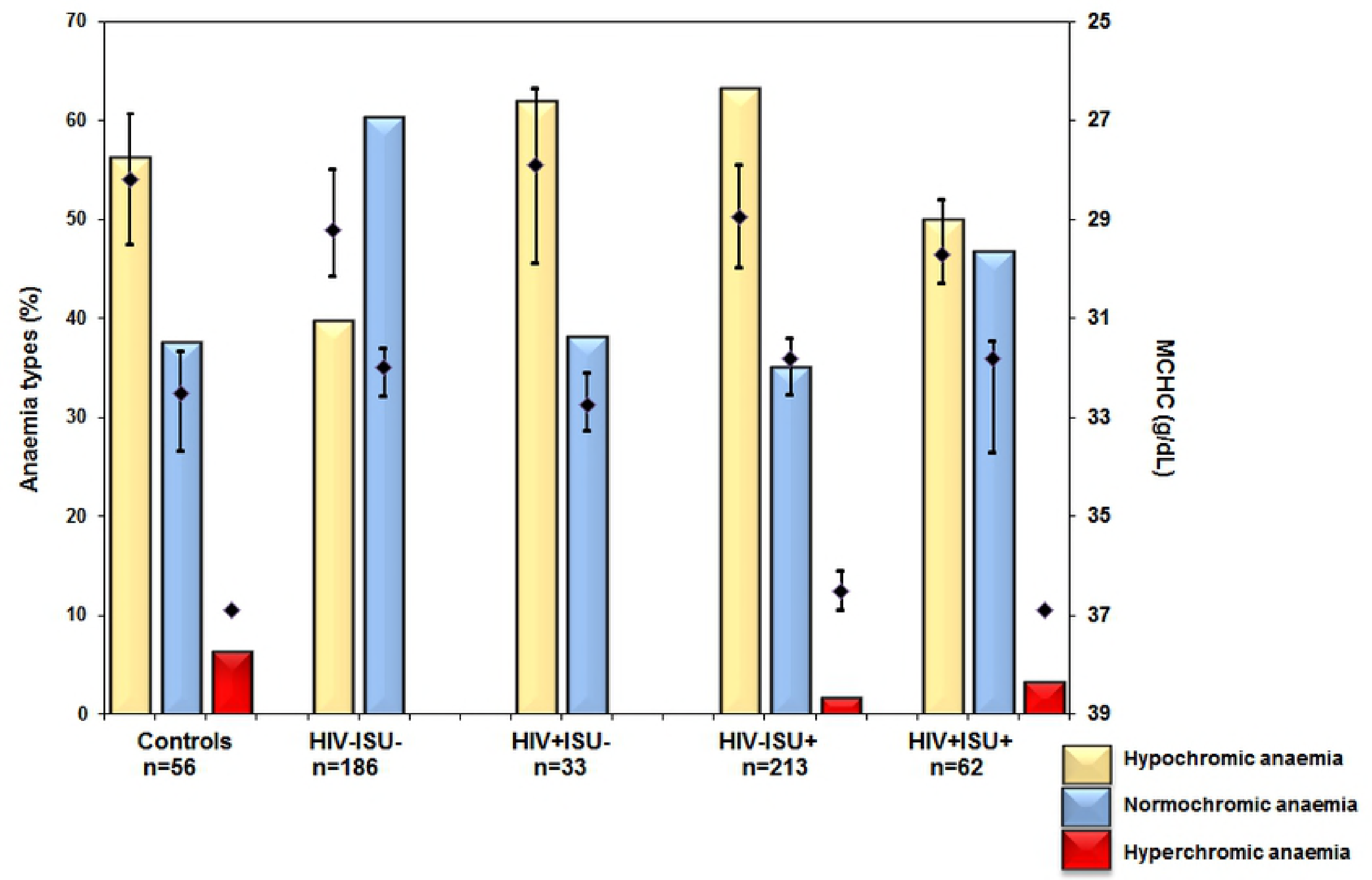




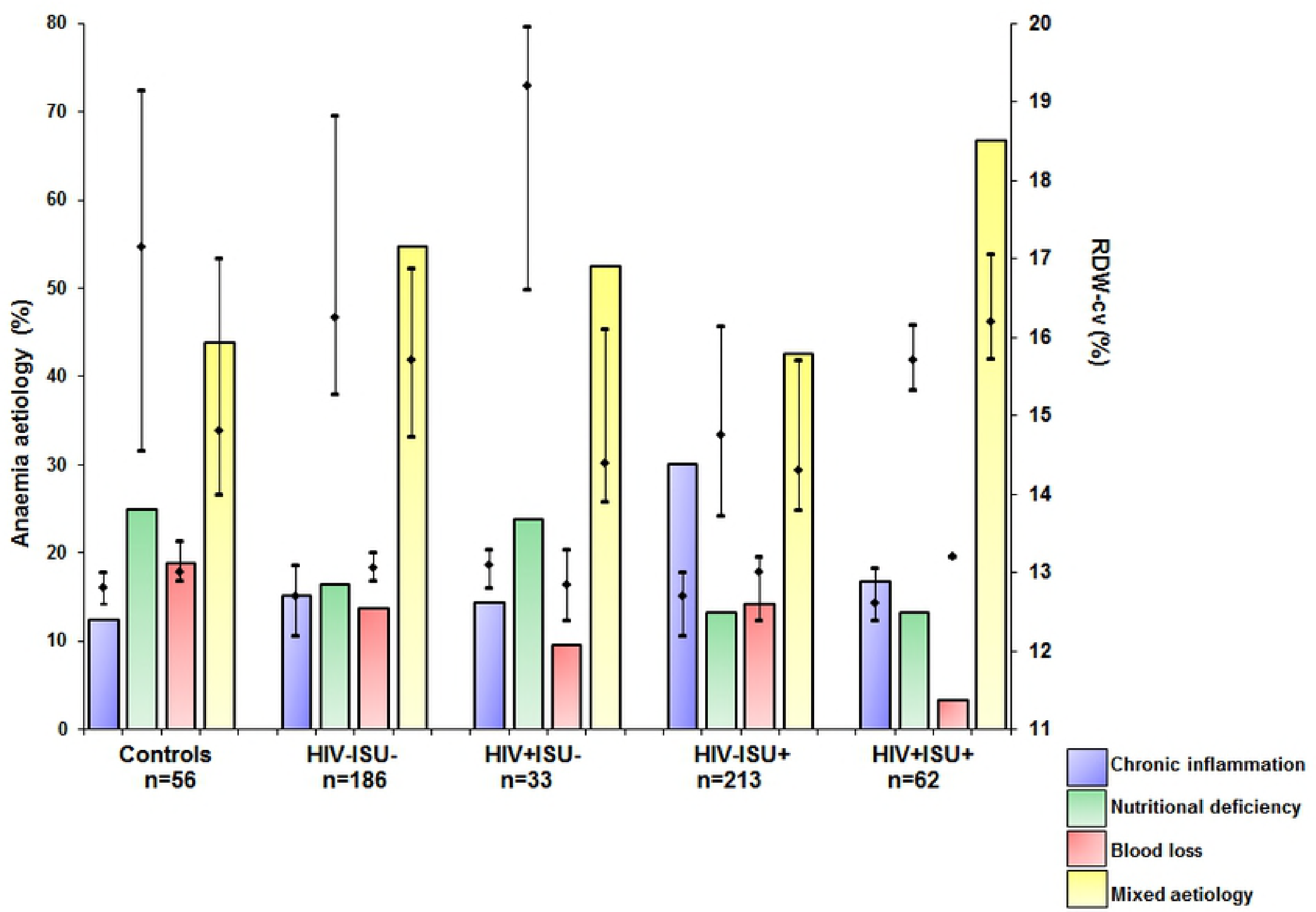

